\title{
The Use of Bisphosphonate-Hydroxyapatite Composite in Bone Augmentation
}

\author{
SORIN CRISTIAN DOCA ${ }^{1}$, GABRIELA VLASE ${ }^{2 *}$, TITUS VLASE ${ }^{2}$, ATENA GALUSCAN ${ }^{1}$, \\ OCTAVIA BALEAN ${ }^{1}$, DANIEL NEGRU ${ }^{1}$, DANIELA JUMANCA ${ }^{1}$ \\ ${ }^{1}$ University of Medicine and Pharmacy Victor Babes, Faculty of Medicine, 2 Eftimie Murgu Sq., 300041, Timissoara, \\ Romania \\ ${ }^{2}$ West University of Timisoara, Faculty of Chemistry, Biology, Geography, Center- Thermal Analysis in environmental \\ problems, 16 Pestalozzi Str., 300115, Timisoara, Romania
}

Abstract. A good bone augmentation and regeneration depends essentially on the use of a high biomimetic hydroxyapatite, respectively of an osteoclast apoptosis promoting compound. The last one, used in oral or injectable form, leads to different gastrointestinal side effects. We suggested and studied, at non-clinical level, a composite of sodium alendronate linked on a biogene hydroxyapatite. The composite was obtained by putting an aqueous solution of alendronate into a suspension of hydroxyapatite in acetone. By physico-chemical methods the binding of alendronate (ALE) on hydroxyapatite was proved, the content of ALE in the composite being $22 \%$. The patients can benefit from this composite due to a total elimination of gastrointestinal side effects as a consequence of limiting the bioactivity only locally.

Keywords: osteointegration, bisphosphonate, gastrointestinal diseases, alendronate - hydoxyapatite compound

\section{Introduction}

Bone is the tissue with the highest transplant and implant frequency. Therefore the interest for developing new biocompatible and biomimetic materials for bone augmentation in both orthopaedic and dentistry practice is understandable.

From a biomimetic point of view the bone is a natural composite in which the mineral component is deposed on an organic matrix [1,2]. The mineral/anorganic component is hydroxyapatite (HA) and the organic one is the colagene I. Of course the quantitative composition depends on the specific tissue (Table 1 and 2).

Table 1. Enamel and dentin composition (\%) [3]

\begin{tabular}{|c|c|c|c|}
\hline & Anorganic substances & Organic substances & Water \\
\hline ENAMEL & 96 & $1.3-1.7$ & 2.3 \\
\hline DENTIN & 70 & 20 & 10 \\
\hline
\end{tabular}

Table 2. Chemical and structural comparison between teeth, bone and HA [4]

\begin{tabular}{|c|c|c|c|c|}
\hline & \multicolumn{3}{|c|}{ \% mass } & HA \\
\cline { 2 - 5 } & Enamel & Dentin & 34.8 & 39.6 \\
\hline Calcium & 36.5 & 35.1 & 15.2 & 18.5 \\
\hline Phosphorous & 17.1 & 16.9 & 1.71 & 1.67 \\
\hline Report Ca/P & 1.63 & 1.61 & 65 & 100 \\
\hline Inorganics total & 97 & 70 & 25 & 0 \\
\hline Organics total & 1.5 & 20 & 10 & 0 \\
\hline Water & 1.5 & 10 & & Bone \\
\hline
\end{tabular}

\footnotetext{
*email: gabriela.vlase@e-uvt.ro
} 


\section{Hydroxyapatite}

HA is the main human skeletal crystalline component that was first synthetically produced around 1970 and used since 1980 as bioactive material [5]. Hydroxyapatite (HA), is a a very known chemical compound natural occurring mineral of calcium apatite with the formula $\mathrm{Ca}_{10}\left(\mathrm{PO}_{4}\right)_{6}(\mathrm{OH})_{2}$ to denote that the crystal unit cell comprises two entities [6]. Compared to enamel, the dentin contains only half of the amount of hydroxyapatite, having smaller crystals and containing less carbon. Thus due to the structure less mineralized. The dentin is softer than enamel, which allows a more rapid evolution of decay [7].

But there are some important differences between the common HA and that in bone. The HA crystallite in bone has a different dimension from the bulk one (acicular form of 200- $400 \mathrm{~A}$ in bone, respectively $1400 \mathrm{~A}$ in enamel) [8]. And these crystallites are deposited on the colagenic macromolecular chain; as a matter of fact a peculiar mezostrocture of HA is formed, strongly dependent on the tertiar structure of the colagenic chain [9-11].

This mezostructure of HA determines the biomimetics of an implant piece. The clinical success of an implant (dental or orthopedic) depends essentially on the bone-implant osteointegration, and even if $\mathrm{HA}$ is totally biocompatible, essential remain the biomimetic properties of the material used by the implant pieces.

In human body the proteic calcium receptor contains 1078 aminoacids and has a level of $93 \%$ the same sequences with the bovine calcium receptor [12]. This leads to a similar mezostructure and explains why the HA of bovine origin is very often used for human bone augmentation.

With synthetic HA there are two troublesome properties:

- a low osseointegration rate due to a more compact crystalline structure in comparison with the mezostructure of a biogenic HA;

- weak physical properties; bulk HA is very brittle, therefore a rational technological solution is to cover a metallic piece (especially titanium) with HA [13,14].

With HA coated surfaces the number of binding cells are significant higher in comparison with a titanium surface [15]. Hystologically, it was proven that on HA surfaces, the bone mineralization occurs directly on HA, without intermediate fibrous tissue, while on titanium surfaces the predomination of fibrous tissue was observed, with scarce zones of direct contact with the bone [16].

Regarding an improved biomimetism of synthetic HA, a series of attempts including nonconventional synthesis ( for instance biomimetic fluids or template effect ) were performed [17-20]. But nowadays, the best osseointegration properties are presented by the biogene HA (bovine, equine).

\section{Bisphosphonates}

Bisphosphonates have long become an integral part of therapy in benign and malignant metabolic bone diseases, such as Paget's disease, osteoporosis and tumour-associated hypercalcaemia and osteolysis, because of their ability to inhibit bone loss [21]. Their activity on osteoclast is also related to adverse events as damaged bone healing and remodeling processes that have as consequence an augmented risk of developing osteonecrosis of jaw, a serious and debilitating condition, in patients subjected to surgical dental procedures as extraction or implant placement [22].

The bone, unlike other tissues, can regenerate itself, as a consequence of a sensible equilibrium between osteoclast and osteoblast activity. An inhibition of the osteoclast mediated bone resorbtion leads to a faster regeneration and a higher bone density. A class of chemical compounds, the bisphosphonates, BP (Scheme 1), proved their bioactivity in the inhibition of the osteoclast activity [23 - 25]. An inhibition of the bone resorbtion is of interest for the osteointegration. 


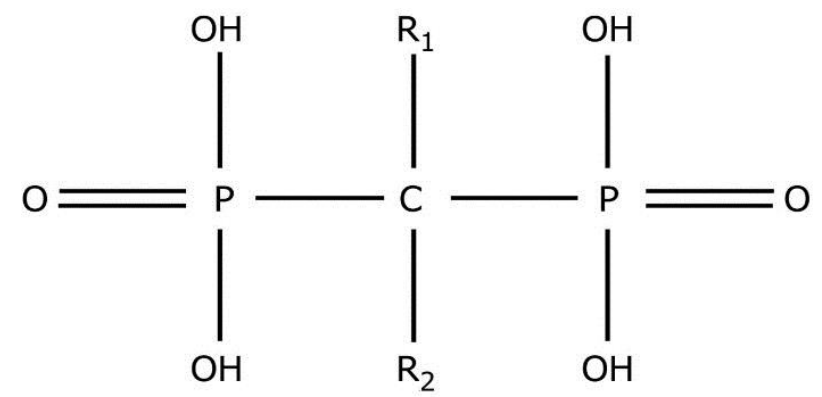

Scheme 1. Bisphosphonic acid (general formula)

The bisphosphonates are compounds with a large molecular volume, a very high negative charge and a very low lipophylicity, consequently a difficult transcellular transport and a weak absorbtion by the gastrointestinal tract. Supplementary, the presence of $p \mathrm{H}$-sensible chemical groups $\left(\mathrm{OH}, \mathrm{NH}_{2}\right)$ determines a significant influence of food and drinks on BP's bioavailability. Due to the P-C-P bridge, BPs are rather not affected by the metabolic transformation and therefore are eliminated through the renal system unchanged. Significant is the half-life in plasma, of 1-2 h, respectively in bone, over 10 years [26].

The citotoxicity of BPs is obvious and understandable, taking into account its similar, but not identical, structure with pyrophosphate [27]. BPs present a very high affinity for HA, due to the similarity between the phosphonate group and the phosphate ion. After adsorbtion and bonding on the HA surface of a bone, the BP molecules are picked up by the osteoclasts. Inside of them, BPs exert its toxicity directly or by connection with the specific biochemical processes in osteoblastes. Especially affected are: the synthesis of lactic acid [28] and prostaglandyne [29], respectively the multiplication of osteoclasts citoskeleton [30]. BPs attain the intracellular environment by pinocytose or fagocytose. The result is an inhibition of bone resorbtion.

Over many years of BP administration, a series of side effects were observed. BPs inhibit proliferation of epithelial cells and frustrate the healing of soft tissues [31]. Therefore the unmetabolized BPs present in the gastrointestinal tract determines some problems, most common being abdominal pain, dyspepsia, acid regurgitation, nausea, abdominal distension, constipation, diarrhea, flatulence, esophageal ulcer, gastritis, gastroesophageal reflux. Besides these common side effects, other problems have occured, in a lower percentage: gastric ulcer, esophagitis, esophageal erosions, melena, dysphagia, vomiting, esophageal stricture, oropharyngeal ulceration, upper gastrointestinal PUB (perforation, ulcers, bleeding) [32 - 35]. And this is as much important as oral administration is the principal receiving way; much smaller is the population receiving intravenous administration, because this way favors the bisphosphonate associated osteonecrosis [36].

Sodium Alendronate, ALE, (in Scheme 1, R1 is $\mathrm{OH}$ and R2 is $\left.\left\{\mathrm{CH}_{2}\right\}_{3} \mathrm{NH}_{2}\right\}$ ) was introduced in 1995 in osteoporosis therapy, as tablets or oral suspension, either for daily use $(10 \mathrm{mg} / \mathrm{day})$ or weekly dose of $70 \mathrm{mg} /$ week. A recent study [37] on these side effects offers alarming data: almost $30 \%$ of the patients treated with a commercial product, FOSAMAX, containing Sodium Alendronate, present gastro-intestinal symptom, abdominal pain (6.6\%), nausea (3.6\%), dyspepsia (3.6\%), constipation $(3.1 \%)$, diarrhea $3.1 \%)$, etc. Important is the conclusion that the frequency is not related to the dosage: for instance, with a dose of $70 \mathrm{mg}$ weekly, the occurrence of abdominal pain is the same as with a dose of $10 \mathrm{mg}$ daily, similar with a $35 \mathrm{mg} /$ week compared to $5 \mathrm{mg} / \mathrm{day}$.

Even if today more active bisphosphonates are in clinical use (Risendronate in ACTONEL, Zolendronate in ZOMETA), the problem on induced gastro-intestinal side effects remains [38].

\section{Topics}

The topic of this paper is to suggest and describe a solution to eliminate (or at least reduce) these side effects, and consequently, enhance the benefits of BP's therapy in bone augmentation. The idea is to restrict the BP bioactivity, i.e the inhibiton of bone resorbtion, only to the therapeutically interested 
area (loco dolenti), without spreading this compound in the entire body. Especially the elimination of BP's presence in the gastrointestinal tract is desired. The proposed solution is to set down a BP compound on HA. This paper will describe and characterize a composite of ALE/HA type, more stable and less harmful for the body, especially for the gastrointestinal tract. The obtained material will be characterized by FTIR and EDX spectrometry and the amount of deposed ALE will be determined by comparative thermogravimetry. The irreversibility of ALE bonding will be tested by searching on the characteristic amino group of ALE after 24 and $72 \mathrm{~h}$ of composite immersion in water. So the premise for a prolonged contact time between ALE and the host bone tissue will be created, without the danger of BP's spreading in the entire host body and especially, without the presence in the gastrointestinal tract.

\section{Materials and methods}

Hydroxyapatite (Merck Sharp\&Dohme) is a granulated biogene HA, used in dental practice for bone regeneration. The raw material was a bovine spongious bone. We selected this material taking into account that the colagenic substrate of the bovine bone is over 93\% similar to the human one, so the condition of biomimetics is satisfied.

Alendronate trihydrate, $\mathrm{M}=325$, from Sigma.

Spectrometry was performed on a SPECTRUM 100 (Perkin-Elmer) device using the UATR technique.

Thermoanalytical curves were obtained by a DYAMOND (Perkin-Elmer) thermobalance in synthetic air (Linde Gas 5.0) atmosphere $\left(100 \mathrm{~mL} / \mathrm{min}\right.$ ) and a heating rate of $10^{\circ} \mathrm{C} / \mathrm{min}$.

EDX diagrams were obtained on a FEI Quanta 250 equipment.

Qualitative amino group identification was based on the color reaction with ninhydrine [39]: equal volumes of the researched aqueous solution, respectively a ninhydrine containing methanol solution of $0.05 \mathrm{M}$ sodium bicarbonate were mixed and measured at $568 \mathrm{~nm}$.

\section{Results and discussions}

\section{Composite preparation}

The solubility of ALE is $7.7 \mathrm{mg} / \mathrm{L}$ [40], so relatively diluted solutions will be used; HA is insoluble in common solvents. The setting of ALE on HA is determined by a brutal change of the environment polarity. An obvious condition is that both liquids are completely mixable.

A suspension of 1:10 (mass parts) HA: acetone was put into a teflon vessel, at room temperature and 38 parts of a $0.7 \%$ ALE aqueous solution was drop wise added while stirring continuously. After a $24 \mathrm{~h}$ maturation period at room temperature, the vessel with the mixture was put into a microwave oven (a commercial ELTA) and was irradiated at low power (150W) until the powder was dry (approx. $90 \mathrm{~min})$.

\section{Composite characterization}

The irreversibility of ALE setting was tested by putting $0.2 \mathrm{~g}$ of composite powder into $5 \mathrm{ml}$ distilled water. After 24, respectively $72 \mathrm{~h}$ at room temperature the supernatant was tested for the presence of ALE. The qualitative test for amino group (with ninhydrine) gave a negative result, and this is not surprising. Indeed, there is a high chemical and sterical similarity between the phosphate anion on the HA surface and the phosphonate groups of ALE. Also an electrovalent bond between the ionized phosphonate groups and the $\mathrm{Ca}^{2+}$ cations of the HA surface takes place. Also, the possibility of a N-H-O bond between the amino group of ALE and the phosphate anion was reported [41]. All these above mentioned facts are arguments for a very stable bonding of ALE on HA surface, so the decreasing osteoclastic activity will manifest itself locally for a long time. The restricted area of ALE's bioactivity and the retardance of its spreading into the body will lead to the absence of any gastrointestinal side effects. 
There are also other significant physico-chemical data for the composite charcterization. The EDX spectrum in Figure 1.

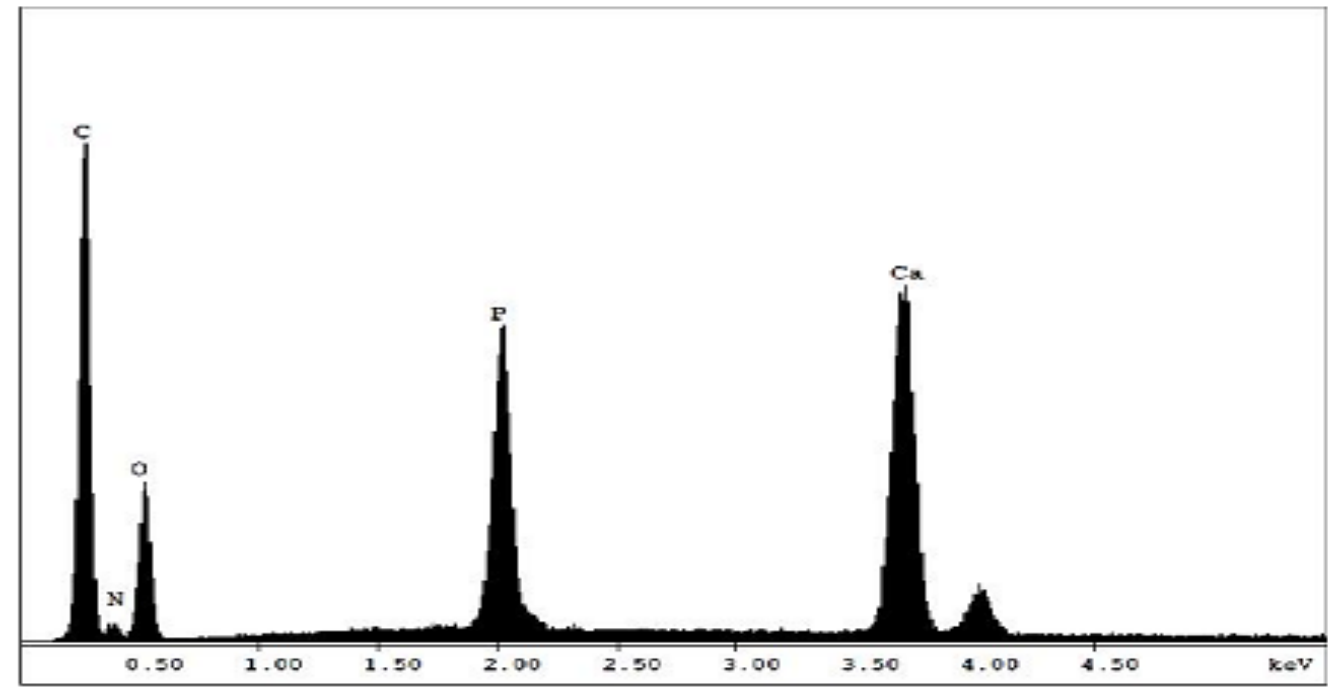

Figure 1. EDX spectrum of the composite

EDX spectrum of the composite indicates the presence of nitrogen in the composite, i.e the presence of ALE (the nitrogen signal is due to the amino group).

The binding of ALE on HA was verified also by IR spectrometry (Figure 2).

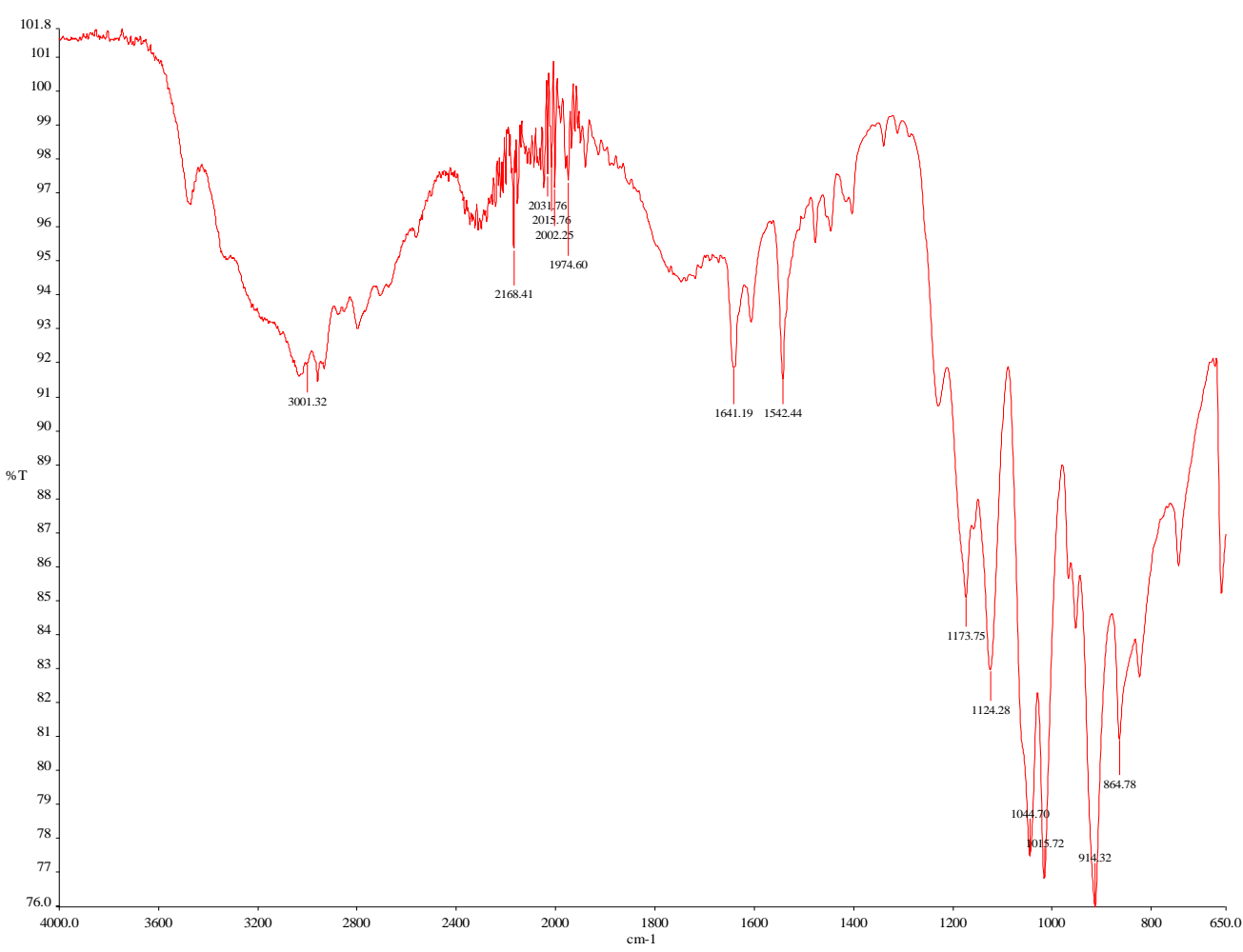

a) Alendronate 


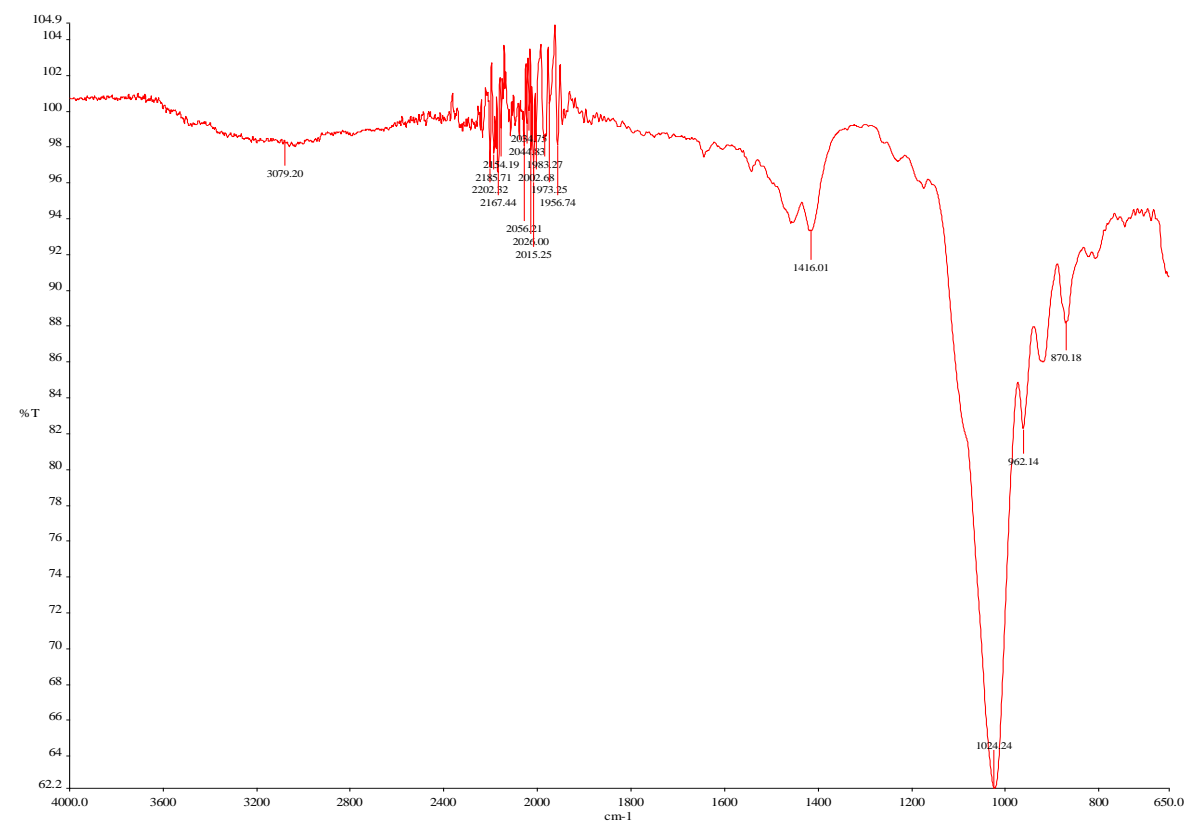

b) Composite

Figure 2. FTIR-UATR spectra of a) Alendronate;b) Composite

According to the spectrum of ALE the mark of phosphonate group between 864 and $1174 \mathrm{~cm}^{-1}$ and the characteristic peaks at 1542 and $1640 \mathrm{~cm}^{-1}$ are observed. According to the composite spectrum the strong signal at $1025 \mathrm{~cm}^{-1}$ is assigned to the phosphate anion. Remarkable is that the characteristic peaks of ALE are moved to a lower wave number (for instance, from 1542 to $1415 \mathrm{~cm}^{-1}$ ), this being a spectrometrical confirmation of ALE bonding on the HA surface.

Hydroxyapatite is known as a very stable compound. The question is if the thermal stability of ALE is changed. In a previous paper [42] the thermal behaviour of sodium alendronate was presented. It was proved that a deamination occurs at $260^{\circ} \mathrm{C}$, and a very sharp and good defined dehydration peak is present at $130^{\circ} \mathrm{C}$. This last one will be used for quantitative determinations.

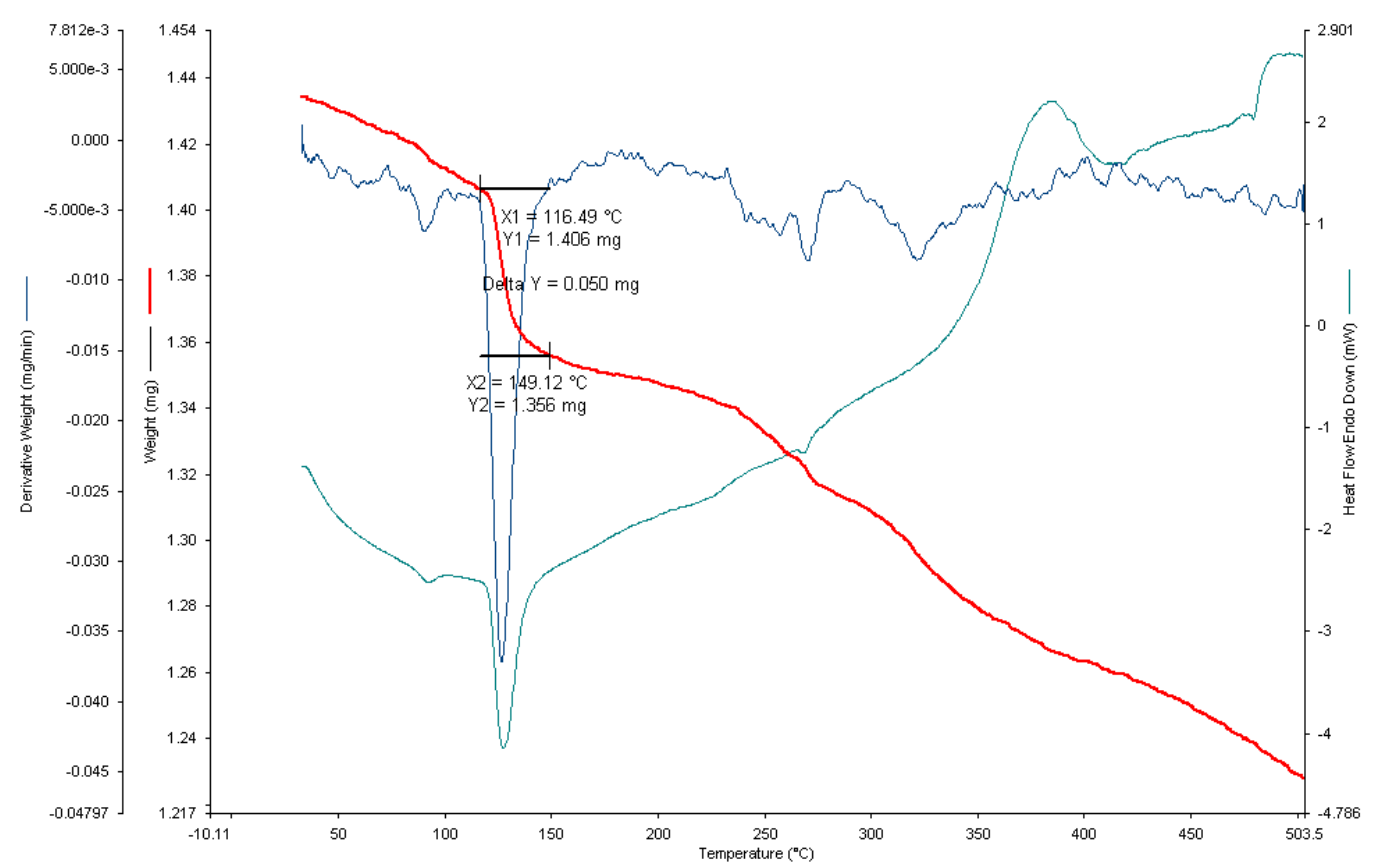

Figure 3. Thermoanalytical curves of composite 
According to the diagrams in Figure 3, the mass loss between 116 and $149^{\circ} \mathrm{C}$ (with a maximum at $130^{\circ} \mathrm{C}$ ) is $3.56 \%$. With pure ALE the mass loss for the same process is $16.2 \%$ [42]. It means that the quantity of ALE in the composite is $21.9 \%$ (considering the HA as very thermostable). This surface concentration is in agreement with that used in biological tests [43], and the quantity of the active compound is enough for a long time activity (min. six month). Of coarse, the quantity of ALE can be varied by a simple change of the acetone suspension : aqueous solution mass ratio.

\section{Conclusions}

The improvement of bone turnover and bone augmentation is possible by pharmacological intervention in the osteoclast-osteoblast balance. Administration (oral, intravenous, etc) of bioactive compounds of bisphosphonate types generates a series of gastrointestinal side effects.

Taking into account the hypothesis that an osteoclast inhibitor drug preserves its ability to induce osteoclast apoptosis when linked on a hydroxyapatite surface, a composite was prepared by setting sodium alendronate from an aqueous solution onto hydroxyapatite being in suspension. The setting of alendronate was favoured by changing the polarity of the fluid environment, i.e the aqueous alendronate solution was put into an acetone suspension of hydroxyapatite.

The linkage of alendronate on the hydroxyapatite surface was researched by physico-chemical and instrumental methods, proving the strong bonding of the bioactive compound.

The presented study is at a non-clinic level and suggests a material for bone implants or regeneration with benefits for patients due to the local bioactivity, without spreading into the entire body, and obviously, without any known side effects. The use of a biogene hydroxyapatite leads to a very high biomimetics, i.e an easy osteointegration.

\section{References}

1. LARSON T.F, MARTINEZ J.M.M, VALLES J.L. Biomaterials for Healthcare-A Decade of EUfunded research. European Commission. ISBN 92-79-05045-9.

2. ROVERI N, FORESTI E, LELLI M, LESCI I.G, MARCHETTI M. Microscopic investigations of synthetic biomimetic hydroxyapatite, Microscopy: Science, Technology, application and Education. A Mendez-Viks si J. Diaz (Eds) C FORMATEX, 2010:1868-1879.

3. GOTIA S.R.: Sistemul oro-facial. Notiuni de fiziologie, ed II, Mirton(EDS), Timisoara, 1999

4. AL-SANABANI J.S, MADFA A.R, AL-SANABANI F.A. Application of Calcium Phosphate Materials in Dentistry. Int. J. Biomaterials, 2013: ID 876132

5. JUMANCA D., MATICHESCU A., GALUSCAN A.: An Experimental Method of Producing Hydroxyapatite, Rev. Chim., 69 (6), 20181506.

6. JUMANCA D., GALUSCAN A., PODARIU A., ARDELEAN L., RUSU L.C.: Nanohydroxiapatite for Dental Enamel Remineralisation, Rev. Chim., 64(5), 2013, 554.

7. GALUSCAN A., JUMANCA D., PODARIU A., ARDELEAN L., RUSU L.C.: Evaluation by Fluorescent Light of Chemo-Mecanical Treatment of Caries Removal Using Carisolv. Rev. Chim., 63(9), 2012, 949.

8. DOROZHKIN S.V. Bioceramics based on calcium orthophosphate. Glass Ceram 2007: 64: 442-447 9. MCQUEEN D, SUNDGREN J.F, IVANSSON B, LUNDSTROM I, EKENSTAM B, STEVENSSON A, BRANEMARK P.I, ALBREKTSSON T. Auger electron spectroscopic studies of titanium implants. in Lee A.J.C, Albrektsson T, Branemark P.I, editors "Clinical Applications of Biomaterials", Wiley, New York,1982: 179-185

10. KASEMO B, LAUSMAAN J. Surface science aspects on inorganic biomaterials. CRC Crit Rev. Biocomp 1986; 2: 335-80

11. KASEMO B, LAUSMAAN J, Biomaterials from a surface science perspective, in: Ratner B.D. Surface Characterization of Biomaterials, Elsevier (Eds) New York, 1988: p1-12

12. NEMETH E.F. $\mathrm{Ca}^{2+}$ receptor-Dependant Regulation of cellular functions. NIPS. 1995;10:1-5 
13. WONG M, EULENBERGER J, SCHENK R, HUNZIKER E. Effect of surface topology on the osteointegration of implant materials in trabecular bone. J. Biomedical Material Research. 1995; 29:1567-1575.

14. CAO N, MA Q.S, Sui J.L. The experiment of pasma-sprayed HA coatings on carbon/carbon composites in bone. Surface Review Lett.2006; 13: 423-8.

15. OKAMOTO K, MATSUURA T, HOSOKAWA R, AKAGAWA Y. RGD peptides regulate the specific adhesion scheme of osteoblasts to hydroxyapatite, but not to titanium. J. Dental Research, 1998; 77:481-487.

16. THOMAS K.A, KAY J.E, COOK S.D, JANKO M. The effect of macrotexture and hydroxyapatite coating on the mechanical strenghts and hystologic profiles of titanium implant materials. J. Biomedical Materials Research. 1987; 21:1395-414.

17. IOITESCU A, VLASE T, VLASE G, ILIA GH, DOCA N. Synthetics and characterization of hydroxyapatite obtained from different organic precursors by sol-gel method. J.Therm.Anal.Cal. 2009; 92: 937-942.

18. MORAR I.R, IOITESCU A. I, DOCA N. Synthetics and characterization of hydroxyapatite obtained by precipitation from simulated body fluid. J.Optoelectron. Adv.Mat. 2009; 1: 17-9.

19. STEVENS M.M. Biomaterials for bone tissue engineering. Materials Today 2008; 11: 18-25.

20. PEPLA E, BESHERAT L.K, PALAIA G, TENORE G, MIGLIAN G. Nano-hydroxyapatite and its applications in preventive, restaurative and regenerative dentistry: a review of literature. Annali di Stomatologia. 2014: V: 108-114.

21. BALEAN O.I., GALUSCAN A., JUMANCA D., FARCAS C., CORICOVAC D., CHIORAN D., LAZUREANU V., PODARIU A.C.: In vitro Effect of Bisphosphonates on Squamous Cell Carcinoma from Tongue Tissue, Rev. Chim., 70 (2), 2019, 663.

22. BALEAN O.I., FLOARE A.D., FOCHT R., JUMANCA D., CORICOVAC D., PINZARU I.,GALUSCAN A., CHIORAN D., CHEVERESAN A., PODARIU A.C.: Comparative Effects of Oral and Injectable Bisphosphonates in Primary Human Gingival Fibroblasts, Rev. Chim., 70 (9), 2019, 3325.

23. EPPLE M, GANESAN K, HEUMANN K. Applcation of calcium phosphate nanoparticles in biomedicine. J. Materials chemistry. 2010; 20:18-23.

24. HENCH L.L, WILSON J. An introduction to Bioceramics. World Scientific. 1993.

25. Le Geros R.Z. Calcium phosphate materials in restorarive dentistry: a review. Advances in Dental Research. 1988; 2:164-180.

26. HENCH L.L. Bioceramics: from concept to clinic. J. Amer. Ceramic Soc. 1991; 74: 1487-1510.

27. ONY J.L, CHAN D.C.N. Hydroxyapatite and their use as coatings in dental implants: a review. Critical Reviews in Biomedical Engineerings. 1999; 28:1-41.

28. CARANO A, TEITELBAUM S.L, KONSEK J.D, SCHLESSINGER P.H, BLAIR H.C. J.Clin. Invest. 1990; 85:456-461.

29. HOROWITZ S.M, ALGAN S.A, PURDON M.A. J. Biomed. Mater. Research. 1996; 31:91-96.

30. ROGERS M.I, WATTS D.J, GRAHAM R, RUSSELL R, Amer.Cancer Soc.(1997).

31. MALDEN N, BELTES C, LOPES V. Dental extraction and bisphosphonates: the assessment, consent and management, a proposed algorithm. British Dental Journal. 2009; 206: 93-98.

32. Dental Management of Patients Receiving Oral Bisphosphonate Therapy. Expert Panel Recommendations, Report of the Council of Scientific Afairs, July 2008, American Dental Association.

33. CRYER R, BAUER D.C. Oral bisphosphonates and upper gastrointestinal tract problems: what is the evidence, Mayo Clin. Proc. 2002; 77:1031-1043.

34. LOWE C.E, DEPEW W.T, VANNER S.J. Upper gastrointestinal toxicity of alendronate. Amer. J. Gastroentero. 2000; 95:634-640.

35. BLACK D, SCHWARTZ A, ENSRUD K, a 5 year randomized trial of the long term efficacy and safety of alendronate. J. Bone Miner. Metab. 2004; 19:S45 abst. 
36. MIGLIORATI C.A. Bisphosphonates and oral cavity avascular bone necrosis. J.Clin. Oncol. 2003;21: 4253-4254.

37. CUNHA J.P. (Medical Editor). Fosamax Side Effects Center. RX List. 26/8/2015.

38. ROVERI N, FORESTI E, LELLI I.G, MARCHETTI M. Microscopic investigations of synthetic hydroxyapatite, Microscopy: Science, Technology, Application and Education. A. Mendez-Viks and J. Diaz (Eds) FORMATEX 2010: 1868-1879.

39. TAHA E.A, YOUSSEF N.F. Spectrometric determination of some drugs for osteoporosis. Chem. Pharm. Bull. 2003; 51:1441-1447.

40. ALANNE A.L. et al. Systematic study of the physicochemical properties of a homologous series of amino bisphosphonates. Molecule. 12012; 17:109-128.

41. CANEPA P.et al. Affinity of hydroxyapatite (001) and (010) surfaces to formic and alendronic acids; a quantum-mechanical and infrared study. Phys. Chem. Chem. Phys. 2011; 13:1099-1111.

42. ALBU P, DOCA S.C, ANGHEL A, VLASE G, VLASE T. Thermal behaviour of sodium alendronate. J. Therm. Anal. Calorim. 2017:127:571-576.

43. ENJUANES A. et all. The effect of alendronate on OPG/RANKL system in differentiated primary human osteoblasts. Endocr. 2010; 37:180-186.

$\overline{\text { Manuscript received: } 13.11 .2019}$ 